\title{
Mad. Caillavet y Anatole France
}

7. 5 un asunto bastante viejo, como que remonta a los años de madurez del novelista. En 1887 Julio Lemaître presentó a Mad. Caillavet el autor de unos cuantos volúmencs de prosa y de verso, que comenzaba a adquirir renombre en los ambientes literarios de avanzada. Anatole France era esle escritor. Mad. Caillavet sintió desde el primer momento por su nuevo amigo una estimación singular. En su casa, que conservaba la tradición de los salones clásicos de Francia, se recibía dos días de la semana: los Miércoles y los Domingos. Infaltable desde el primer dia. Anatole France llegó a ser el amigo predilecto de Mad. Caillavet y luego su amante. Detalles de esta liaison existen en gran número. Antes de la muerie del maestro, su secretario Jean-Jacques Brousson habia sido no uno de los primeros pero sí uno de los más indiscretos para revelarlos. No mencionaba Brousson el nombre de -ellas, a quien llamaba sencillamente madame. Pero como no era un misterio el enredo. el libro de Brousson sirvió para precisarlo más perfectamente. Ahora último otra señora. Mme. Pouquet. que fué nuera de Mad. Caillavet, ha publicado todo un libro dedicado a este asunto. No será inútil reșumir en unas cuantas lineas lo que sc sabe al respecto.

Hemos dicho ya que France y la Caillavet se conocieron en 1887 y que desde el primer instante hicieron buena amislad. Mad. Caillavet en ese tiempo vivia la hora cenital de su existencia. Era entonces-escribe un comentarista-una mujer pequeña y gruesa, con la cara encuadrada por rubios rizos sembrados de lazos de terciopelo negro y de pequeñas rosas.s 
Retratos de la época nos la muestran con un rostro amable y dulce, en el cual vaga una sonrisa de inteligencia y de distinción. Sus ojos son claros y el aspecto todo de su fisonomia es sensual y hasla voluptuoso. Sus labios son carnosos; su nariz, roma y graciosamente respingada, y sus orejas, grandes. Un hermoso pelo corona esta cara dulce, unida a un cuerpo regordele por un cuello blanco y grueso. Cuando conoció a France. vivia ya en su residencia definitiva, el hotel que habia pertenecido a Arsenio Houssaye, ubicado en la Avenida Hoche. N. ${ }^{\circ}$ 12, que entonces se llamaba Avenida de la Reina Hortensia. Era una cașa lujosa, compuesta de grandes salones en que se juntaba toda clase de muebles valiosos y objetos de arte. En el salón destinado por Mad. Caillavet a la recepción de sus habifués. se veían siempre instrumentos de música-un piano de concierto. un arpa-junto a vitrinas cargadas de bibelots y a cuadros de buenas firmas. Pero a pesar de lo solemne y amplio de toda la casa. no fáltaban en ella algunos rincones gratos. Uno de estos era seguramente el escritorio en que trabajaba France. Era pequeño. y unas altas estanterias adosadas a la pared y cuajadas de libros lo hacian aún más intimo. En el centro una mesa sencilla; frente a ella un sillón de estilo, y al ofro lado una chimenea de mármol, coronada con un espejo y cubierta con un biombo chino.

Este era el lugar de los suplicios de Anatole France. El ilustre escritor no sentía el menor apego por el trabajo y seguramente en aquella casa su espíritu se sentía más dado a la molicie y al amor que al esfuerzo. Pero Mad. Caillavet era una Venus juiciosa. No le permitia a su amigo sino muy contadas expansiones. El resto del tiempo lo instaba a trabajar. empleando para ello todos los medios a su alcance. Brousson cuenta algunos episodios $\left(^{*}\right)$ bastante reveladores. En alguna ocasión la buena señora habría llegado hasta el colmo de echar llave a Anatole France en su gabinele. para que diera cima a algún artículo o cuento que urgia entregar. Anatole France

(") Véase Anatole France en pantoufles», de Brousson. 
protestaba en todos los tonos contra esta tirania. A sus intimos les contaba que su amante era implacable, que no tenia piedad alguna para con él y que no respelaba el instinto flojo y remolón que lo poseia. Pero las quejas de France no excluian respeto y hasta gratilud. France ha confesado no sólo que sin Mad. Caillavet no habria escrito muchas de sus obras, sino que hasta algunas páginas de ellas deberian llevar la firma de su amiga. Loti y Lemaitre, entre otros, oyeron a Anatole France esta conlesión interesante y peregrina.

Rasgos que nos revelen el grado de amor que reinaba en estas relaciones, parecen ser hasta el momento ignorados. No son conocidas todavia, por ejemplo. las cartas cambiadas entre los dos amantes, a excepción de algunos escasos fragmentos. Cuando Anatole France realizó su viaje por la República Argentina, Mad Caillavet escribió a una amiga; ‘Qué insensato! Ha ido al país de los antipodas a vivir con la cabeza para abajo. en compañia de salvajes, monos y papagayos.s Como buena hija del pais de Francia, Mad. Caillavel confundia de manera deliciosa las nociones geográficas y cosmográficas. Por lo demás. su sentimiento herido por la ausencia bien podia dictarle expresiones atribuladas y no muy exactas. Por su parte. Anatole France escribia a su amiga, con ocasión de otro viaje: -Me siento tonto lejos de usted., Y luego le declaraba: „Horacio aseguraba que Virgilio le habia llevado al partir la mitad de su alma. A mi no me ha quedado tanto.s Cumplido que no por ser tan erudito podemos tachar de frio o de poco expresivo.

La amistad de Mad. Caillavet y Anatole France duró más de veinte años y lerminó con la muerte de ella. En ese periodo el escritor publica sus más valiosas obras y conquista, con una seguridad desconocida hasla entonces y con una serenidad envidiable, los más altos lugares. Cuando publicó eCrainquebille. France reconoce a su amiga el valor de sus relaciones. En el ejemplar que le dedica. conservado celosamente en la Biblioleca Nacional de Francia, escribe: A Madame Arman de Caillavet ce petit livre que sans elle je n'aurais pas fait, car sans elle je ne ferais pas de livres, très respectueusement et très affectueu- 
sement, Anatole France.s No sólo, como hemos dicho, Mad. Caillavet instó a su amigo a trabajar, sino que hasta algunas páginas de sus obras se deben a ella. Pero hay más aún: Anatole France no habria podido escribir, con la brillantez y el valor de realidad que todos admiran en se lys rouge. este libro magnifico sin la cooperación de su amiga. Mad. Caillavet fué, en efeclo. quien introdujo a France en un mundo distinguido y quien le dió a conocer muchos detalles de la vida elegante, inéditos enteramente para el novelista. Ya en la trastienda de cierta nobleza, France pudo descubrir los hilos de la farsa y reir y hacer reir con su juego. Su amiga lo perseguia con su admiración y lo hacía exhibirse y darse pisto. Sin ella. mucha de la fama de France-por lo menos, su fama de salón como espiritu amable, conversador ameno, sutil paradojistahabria quedado en la sombra. En el salón de Mad. Caillavet el novelista no podía estar oculto ni tratar de pasar inadvertido. Es famoso ese breve diälogo: «Monsieur France, vous dormez. je crois?-Non, madame: je refléchis.s En verdad el escritor no reflexionaba sino que dormia. $Y$ entonces era cuando su tirana lo hacia colocarse de pie junto a la chimenea y recitar algunos versos o lecr algunas páginas de su libro en prensa. En ocasiones Mad. Caillavet convertía a France en un instrumento de pelambre y de murmuración mundanos. Brousson, que tanto nos ha dicho en su libro Anatole France en zapatillas». ha conservado la visión de aquellos instantes. El escritor obedecía discretamente a su amiga y narraba el último escándalo - la más picante comidilla social. Pero no era su charla una simple chismografia o un vulgar pelambre. Era una disertación amena, en la cual se mezclaban el hecho escuelo y la divagación del escritor, erudita y disolvente, en forma indisoluble.

Muchos otros detalles tenemos ya sobre esta amistad de más de veinte años, que tuvo tanta influencia en la vida y en la obra de France. Algunos comentadores exageran su importancia. Si Mad. Caillavet no hubiese muerto cuando murió, su amigo no habria asumido tales o cuales actitudes. Si Mad. Caillavet hubiese estado viva, el escritor no habria sido pacifista durante 
la guerra y comunista después de ella. Y sin embargo, parecen olvidar los que tal cosa dicen que fué la misma Mad. Caillavet la que determinó la intervención de France en el episodio Dreyfus. siguiendo una linea de conducta que no era nueva en sus salones. Pero eso no interesa. Recojamos, para finalizar, una anécdota valiosisima que nos cuenta más de un cronista bien informado. En el salón de recibo de Mad. Coillavet, una noche de recepción. a la hora de la comida. .Mme. Arman estaba en su poltrona y $M$. France junto al fuego.s En esos momentos entra un politico. invitado a la comida. El politico en cuestión entró y besando la mano de la dueña de casa con toda la graciano excesiva por cierlo-de que era capaz, se disculpó de llegar demasiado temprano._-Veo que he llegado primeros-dijo.,

Realmente, no era misierio para nadie que en aquella casa vivia en cierlo modo el aulor de .Tais. El y su fiel amiga ya han muerto y el recuerdo de su relación no tiene por qué ser indiscreto ni menguado.

RAÚl SILVA CASTRO. 